\title{
Hybrid cylinder dryer for the drying of sheet-form materials with hot air
}

\author{
Kim, S.I. ${ }^{a^{*}}$; Oh, S.H. ${ }^{a}$; Chun, W.P. ${ }^{a}$; Park, K.H. ${ }^{a}$; Yu, B.H ${ }^{a, b}$
}

${ }^{a}$ Energy Saving Technologies lab. Department of Energy Efficiency and Materials. Korea Institute of Energy Research, Daejeon, Republic of Korea (ROK)

b Energy Conversion System lab. Department of Mechanical Engineering. Chungnam National University, Daejeon, Republic of Korea (ROK)

*E-mail of the corresponding author: praygod@kier.re.kr

\begin{abstract}
In this paper, we introduce a novel energy-efficient dryer that uses hot air as a combined heating method of heat conduction and convection heat transfer. The dryer consisting of rotary cylinders and arched jackets is structurally different from conventional dryers. We designed and built a hybrid 4-cylinder dryer for sheet-form materials. The energy consumption to evaporate unit water is about $930 \mathrm{kcal} / \mathrm{kg}$ moisture from the experimental results of a hybrid 4-cylinder dryer. The hybrid 4-cylinders dryer has a compact structure with about 1/3 of the size of a conventional dryer for the drying of sheet-form materials.
\end{abstract}

Keywords: Dryer; Hot Air; Sheet-form; Energy Efficiency; Hybrid 


\section{Introduction}

Research and development (R\&D) in industrial drying systems has been focused primarily on technological advances that improve drying efficiency and lower energy costs. According to the survey, the annual energy consumption of domestic industrial dryers is about $7 \%$ of the total industrial energy consumption. Since the energy consumed in the drying process for textile/paper is about $30 \%$ to $50 \%$ of the total energy consumption, it is urgent to increase the energy efficiency of dryers for textile/paper. Domestic fabrication technology for dryers is at the level of advanced countries, but the domestic core technologies such as system design, control technology, and post-processing are about $70 \%$ compared to advanced countries and still depend on advanced technology. It is expected that the development of high energy efficiency and commercialization technology in the domestic drying field have a significant effect from the viewpoint of energy saving.

This study proposes a new type of a dryer with high energy efficiency using hot air. The dryer consisting of rotary cylinders and arched jackets is structurally different from conventional textile/paper dryers. The rotary cylinder in contact with the sheet-form materials is thermally optimized through numerical methods. The arched jacket allows the hot air coming from the rotary cylinder to come into contact with the sheet-form materials. The energy consumption to evaporate unit moisture for the proposed dryer is about 930 $\mathrm{kcal} / \mathrm{kg}$ water from the experimental results of a hybrid 4-cylinder dryer.

\section{Drying wet materials and numerical analysis}

\subsection{Drying wet materials}

The drying characteristics of drying wet materials may be determined by a drying curve. Figure 1 shows the drying curves of various textile samples. As shown in Fig. 1, the change in the moisture content of the textile is apparent, but the first and second falling drying-rate period are not clearly distinguished. The feature of the drying curves of the textiles in which the falling drying-rate period is not clearly shown is important in the design of a dryer.

\subsection{Thermal design of a rotary cylinder}

A rotary cylinder in this study uses hot air differently from a conventional cylinder using steam and has fins on the cylinder inner surface for the purpose of improving the heat transfer. Heat flowing into the center of the cylinder is conducted to the cylinder outer surface, and the heat is transferred to the drying wet material in contact with the cylinder outer surface. In this study, numerical analysis is used to calculate the heat transfer 
according to the number and shape of fins. For the shape design of fins, case studies are carried out under the same conditions as Table 1. The optimal shape of the cylinder selected in this study is shown in Fig. 3. The cross-sectional area of the cylinder decreases along the direction of hot air flow and the fin is wavy shape.

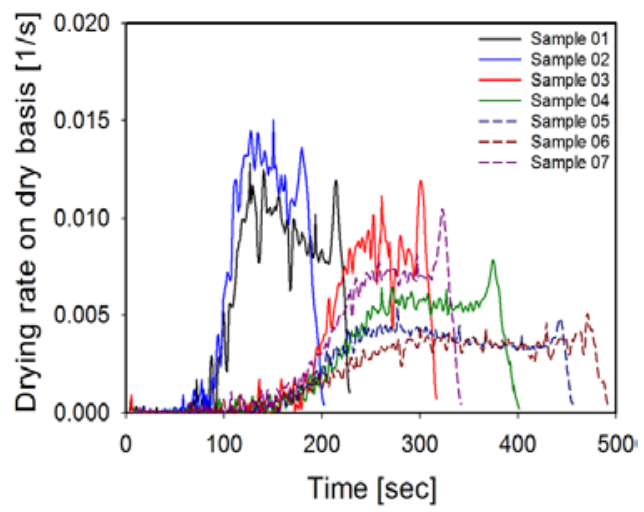

Fig. 1 Drying curves of textile samples.

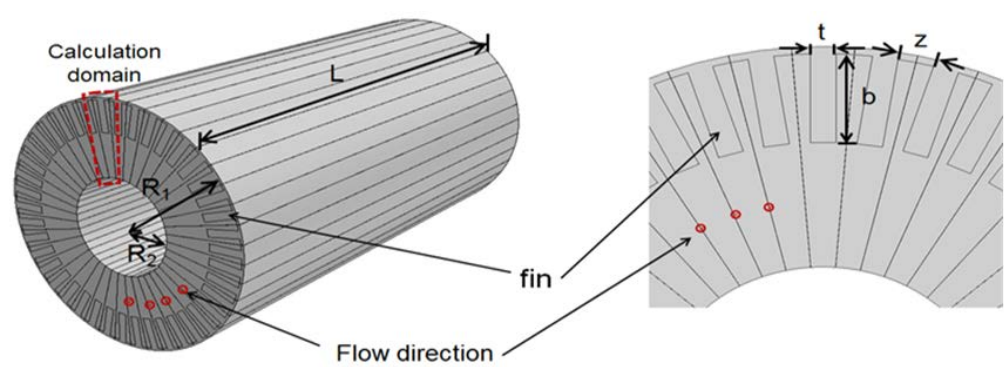

Fig. 2 Rotary cylinder and simulation domain.

Table 1. Constraints for simulation of a rotary cylinder

Inlet temperature of hot air

Outer radius of cylinder

Inner radius of cylinder

Length of cylinder

Hot air velocity

Fin material
$180{ }^{\circ} \mathrm{C}$

$0.25 \mathrm{~m}$

$0.125 \mathrm{~m}$

$2.0 \mathrm{~m}$

$4.5 \mathrm{~m} / \mathrm{s}$

Aluminium 6063-T5 

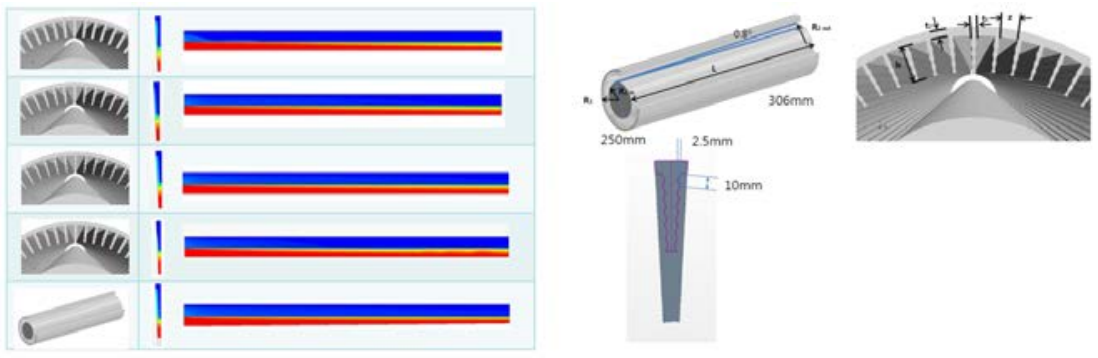

Fig. 3 Temperature variation according to the flow direction of hot air in single fin.

\subsection{Arched jacket}

The hot air exhausted through the cylinder is brought into contact with the drying wet material in the arched jacket. When designing an arched jacket, it is important to have uniform velocity distribution in the direction perpendicular to the flow in terms of drying quality. The numerical analysis approach is used to design the arched jacket. Figure 4 (a) shows that the flow tends to lean toward one side of the jacket in the original design. In order to make the flow of hot air uniform, numerical analysis is conducted to introduce guide vanes and flow analysis according to the change of guide vane shape. The numerical results are shown in Fig. 4 (b).

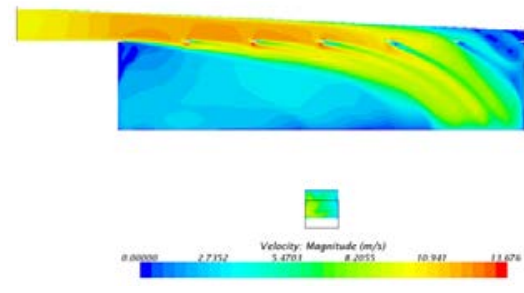

(a)

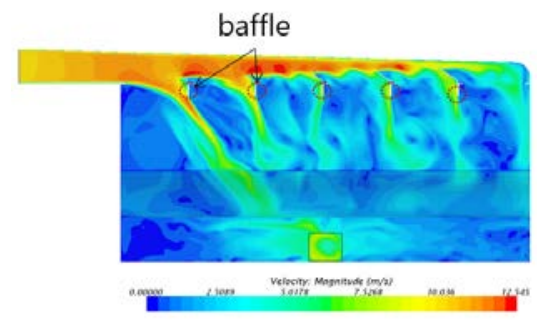

(b)

Fig. 4 Velocity distribution in the arched jacket.

\section{Results and discussion}

\subsection{Dryer with 4-cylinders}

Based on the results from numerical analysis, the dryer with 4-cylinders is fabricated as shown in Fig 5. The dryer has four rotary cylinders, a burner, blowers and other elements. In addition, the dryer is configured to facilitate the management of the apparatus. The hot 
air flow was controlled for the purpose of minimizing the moisture content deviation of drying products in the horizontal direction after drying, and the active control tensioner was installed to reduce the tension acting on the drying wet materials due to the cylinders.

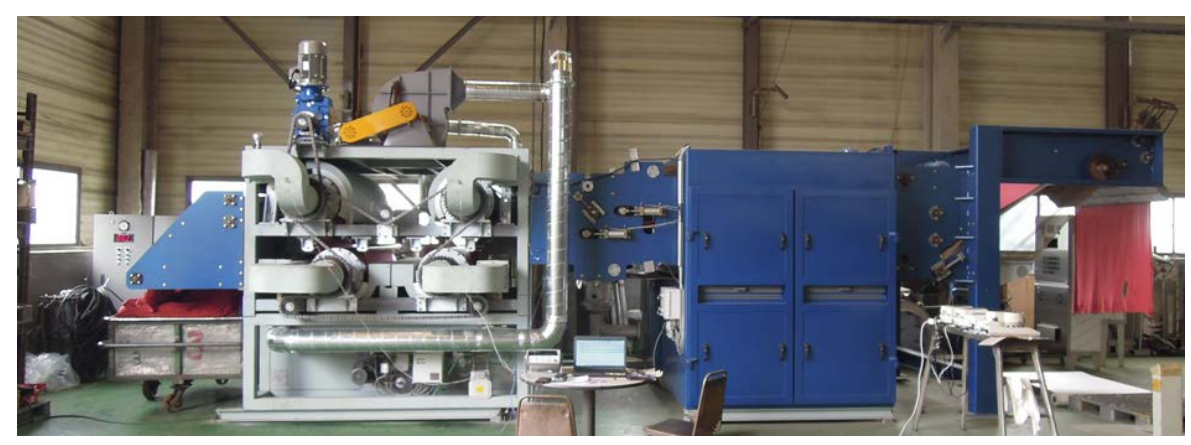

Fig. 5 Dryer with 4-cylinders

\subsection{Temperautre deviation of the drying system}

In this study, the deviation of hot air temperature means the difference between the values of the measured temperature over a certain period of time. The temperature deviation is to confirm the temperature uniformity of the hot air supplied to the drying system and the basic system stability such as the energy efficiency evaluation of the dryer and the temperature stability of the system. The test is performed by measuring the temperature at the inlet of the cylinder for 1 hour, and checking whether the temperature deviation between the maximum temperature and the minimum temperature is within $\pm 5^{\circ} \mathrm{C}$. In the test results, since the temperature deviation is $\pm 2.9^{\circ} \mathrm{C}$, it can be judged that the temperature stability of the system is excellent.

\subsection{Drying efficiency}

Drying efficiency is used to evaluate the energy savings of a dryer. The energy saving of the dryer is compared with the energy consumption of a conventional dryer and the developed dryer. a conventional dryer is a through-flow drying method in which hot air hits onto the surface of textiles. Table 2 shows experimental conditions and drying efficiency. The initial moisture content of the textiles is about 55 w.t\% and the drying capacity is 200 $\mathrm{kg} / \mathrm{hr}$. Energy consumption is measured using an integrating wattmeter and a gas meter. The drying efficiency is defined as Eq. (1). 
Table 2. Comparison of drying efficiency

\begin{tabular}{|c|c|c|}
\hline & Existing dryer & Novel dryer \\
\hline Initial M.C & \multicolumn{2}{|c|}{55 w.t\%(w.b) } \\
\hline Final M.C & \multicolumn{2}{|c|}{3 w.t\%(w.b) } \\
\hline Hot air temp. & \multicolumn{2}{|c|}{$180^{\circ} \mathrm{C}$} \\
\hline Drying capacity & \multicolumn{2}{|c|}{$200 \mathrm{~kg} / \mathrm{hr}$} \\
\hline Drying efficiency & $30.4 \%$ & $58.1 \%$ \\
\hline
\end{tabular}

$$
\varepsilon=\frac{\text { Latent heat of evaporated moisture }}{\text { Total energy of heat and electricity }} \times 100[\%]
$$

As shown in Table 2, the drying efficiency of the developed dryer compared to the conventional dryer shows a great difference. It can be seen that the developed dryer in this study has a drying efficiency twice as high as that of the conventional dryer. The energy consumption to evaporate unit moisture is about $930 \mathrm{kcal} / \mathrm{kg}$ water from the experimental results of the hybrid dryer. The dryer has a compact structure with about $1 / 3$ of the size of the conventional hot air dryer.

\section{Conclusions}

The purpose of this study is to develop a dryer for sheet-form materials with high energy efficiency. The novel dryer is a cylinder type using hot air. While a conventional dryer using only direct heating or indirect heating, the proposed dryer adopts a multiple heating system. The developed dryer dramatically increased the drying efficiency and is a unique device that differentiates from the conventional dryer in the usage of the heat source. In order to utilize a combined heating method of direct heating and indirect heating, precise analysis and complicated design should be performed. We have successfully developed the $200 \mathrm{~kg} / \mathrm{hr}$ dryer with 4 -cylinders through $\mathrm{R} \& \mathrm{D}$. The energy consumption to evaporate unit water is about $930 \mathrm{kcal} / \mathrm{kg}$ water from the experimental results of a hybrid dryer.

\section{Acknowledgements}

This work was supported by the Korea Institute of Energy Technology Evaluation and Planning(KETEP) and the Ministry of Trade, Industry \& Energy(MOTIE) of the Republic of Korea (No. 20172010105940). 